\title{
FUEL CONSUMPTION MEASUREMENT PROTOCOL FOR DIESEL ENGINES
}

\author{
Everton Lopes da Silva, Leonardo Coelho Bergantim, Juliano Pallaoro de Souza, \\ Carlos Roberto Camargo \\ MAHLE Metal Leve S.A. \\ E-mails: everton.silva@br.mahle.com, leonardo.bergantim@br.mahle.com, \\ juliano.souza@br.mahle.com, carlos.camargo@br.mahle.com
}

\section{RESUMO}

Consumo de combustível tem sido um dos mais importantes assuntos em discussão na indústria automotiva. A combinação de políticas ambientais e preço do petróleo tem aumentado a pressão nos fabricantes de veículos para melhoria em eficiência energética dos motores. No entanto, uma vez que os motores tem se tornado cada vez mais eficientes, cada modificação adicional pode ter uma contribuição pequena o suficiente para estar na margem de erro da medição de consumo de combustível. A precisão da medição é influenciada por diversos fatores relacionados ao motor e aos equipamentos, por exemplo, temperatura do ar, pressão atmosférica, poder calorífico do combustível, temperatura do combustível, temperatura do óleo lubrificante, tempo de condicionamento e parâmetros de operação e combustão do motor. O estabelecimento do protocolo de teste para determinação de consumo de combustível em motores Diesel consistiu em definir as condições de contorno que influenciam na medição e que necessitam de controle ou atenção especial para redução da dispersão nos resultados. O protocolo foi validado seguindo as condições definidas e os resultados mostraram que é possível medir com boa precisão, especialmente em cargas altas, com dispersão menor que $0,3 \%$. O artigo apresenta os métodos aplicados para manter as medições controladas e um exemplo de medição para um componente de motor.

\section{INTRODUÇÃO}

Atualmente o meio de transporte mais utilizado no mundo tem sido o automóvel, a grande maioria destes veículos são movidos por motores de combustão interna e queimam combustíveis de origem fóssil, que resulta em emissões de gases nocivos à saúde e que geram impacto ambiental através dos gases de efeito estufa, como o dióxido de carbono $\left(\mathrm{CO}_{2}\right)$.

A eficiência na utilização de combustíveis e a sua relação com a emissão de $\mathrm{CO}_{2}$ tem sido assunto frequente nas discussões da indústria automotiva, governos e órgãos ambientais. Segundo estimativas da IEA (International Energy Agency) [1], as emissões de $\mathrm{CO}_{2}$ provenientes da frota de veículos poderá dobrar entre os anos 2000 e 2050, conforme demostrado na figura 1.

Neste cenário é considerado que a quantidade de quilômetros percorridos por veículos duplicará até 2050 e que haverá uma modesta melhoria na eficiência de 
consumo de combustível dos veículos. No entanto, ainda existe oportunidade para redução adicional através da melhora de eficiência de consumo de combustível da frota circulante em até $50 \%$ até 2050 [2].

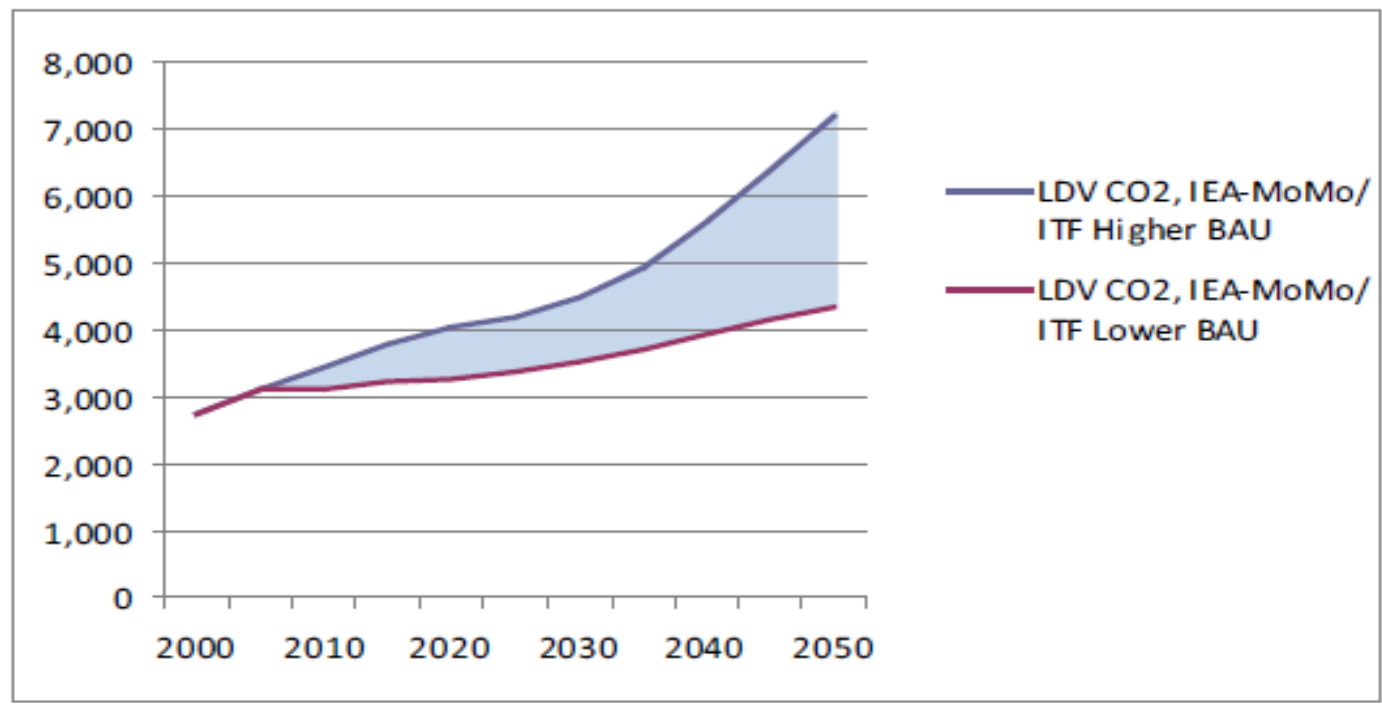

Figura 1. Projeção de emissões globais de $\mathrm{CO}_{2}$ provenientes de carros em $\mathrm{Mt}$ de $\mathrm{CO}_{2}$ equivalente GHG (Greenhouse Gas) [1].

Políticas governamentais têm caminhado no sentido de estimular a redução das emissões de $\mathrm{CO}_{2}$, podendo ser aplicadas penalizações àqueles fabricantes que não cumprirem com as metas estabelecidas. A figura 2 compara as metas de emissões de $\mathrm{CO}_{2}$ projetadas até 2022 em diferentes regiões do mundo.

Actual and Projected GHG Emissions for New Passenger Vehicles by Country/Region, 2002-2022

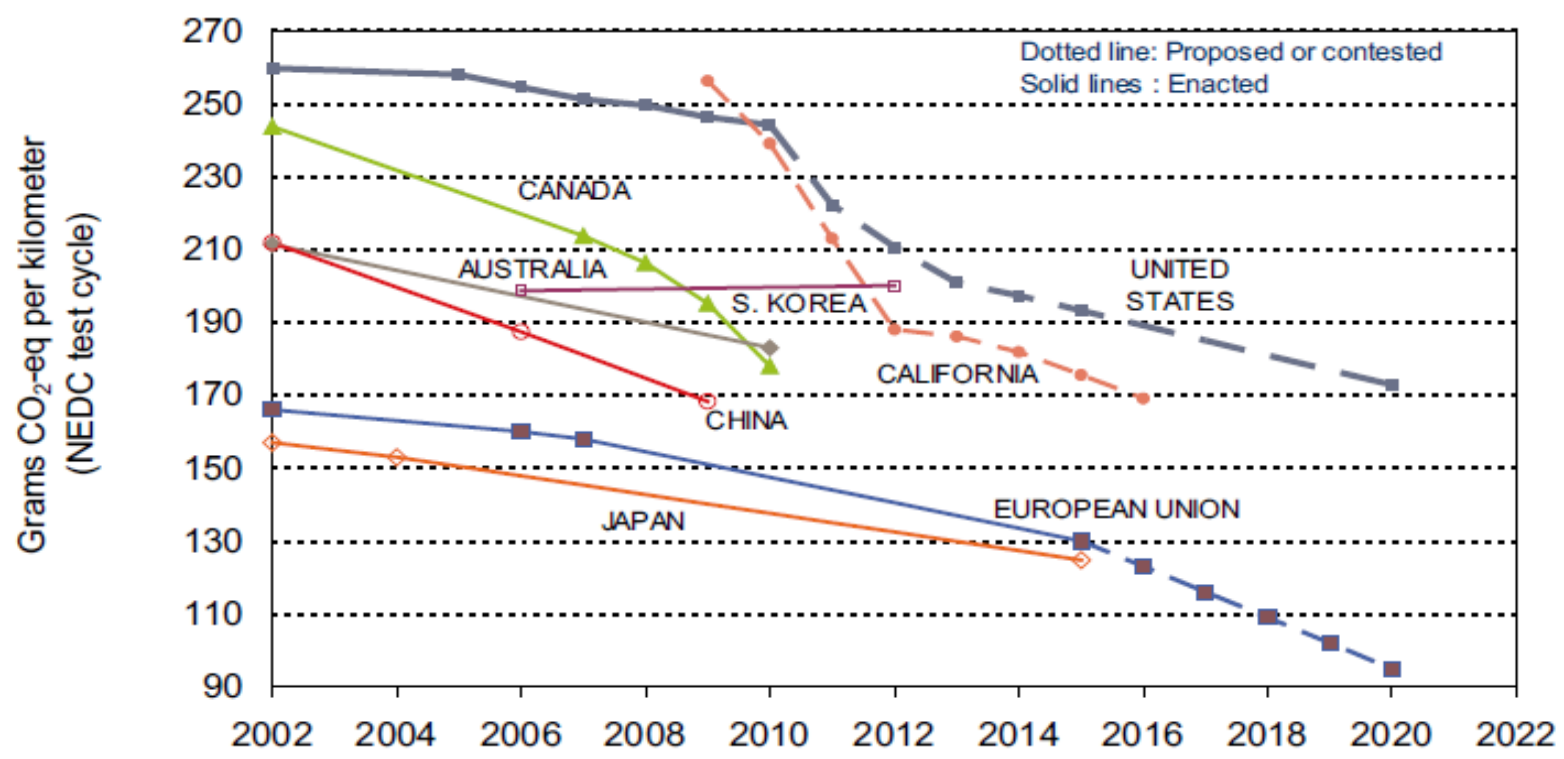

Figura 2. Comparativo de emissão de $\mathrm{CO}_{2}$ para veículos de passageiro em diferentes regiões do mundo[1]. 
É importante ressaltar que as possibilidades de redução do consumo de combustível estão vinculadas ao veículo como um todo, sendo o motor um dos focos para otimização.

No entanto, uma vez que os motores vão se tornado cada vez mais eficientes, cada modificação adicional pode ter uma contribuição pequena o suficiente para ser confundida com erros típicos da medição de consumo de combustível.

Segundo Schantl [3], para que seja possível desenvolver tecnologias para redução de consumo é necessário uma repetibilidade de $\pm 1 \mathrm{~g} / \mathrm{kWh}$ na medição. A repetibilidade da medição pode ser influenciada por diversos fatores como: configuração, instalação, operação e precisão dos equipamentos de medição de consumo, temperatura do ar, pressão atmosférica, poder calorífico do combustível, estabilidade da temperatura do combustível e óleo lubrificante, tempo de estabilização antes da medição, precisão na determinação do torque e na rotação do motor, bem como estabilização de parâmetros do motor que influenciam na combustão.

Neste trabalho será apresentado o protocolo de teste proposto para determinação de consumo de combustível em motores Diesel em banco de provas de motores (dinamômetros).

A metodologia de abordagem para elaboração deste protocolo consistiu principalmente em definir as condições de contorno que influenciam a medição e que necessitam de um controle ou atenção especial para redução da dispersão, bem como definir a sequência de execução do teste e os critérios de aceitação do resultado obtido. Isso é chave para o desenvolvimento de novos componentes de motor capazes de reduzir o consumo de combustível.

\section{MATERIAIS}

Conforme citado no capitulo anterior, a necessidade de acuracidade e baixa dispersão nas medições, gerando resultados estáveis e repetitivos, é o principal fator de sucesso deste protocolo, pois permite detectar contribuições pequenas oriundas dos novos componentes.

Os testes realizados para o desenvolvimento do protocolo e os testes descritos neste trabalho foram executados no laboratório de motores do Centro de Tecnologia da MAHLE Metal Leve S/A em Jundiaí - SP. O banco de provas utilizado para os experimentos possui sistemas automatizados de controle dos regimes do motor e aquisição de dados, permitindo assim um processo pouco influenciado pela intervenção humana. Todas as condições de contorno para o funcionamento do motor, tais como, controle das temperaturas de trabalho dos fluidos de arrefecimento e lubrificação, foram controlados de acordo com as faixas normais de trabalho do motor.

O motor instalado no banco de provas é representado na figura 3. 


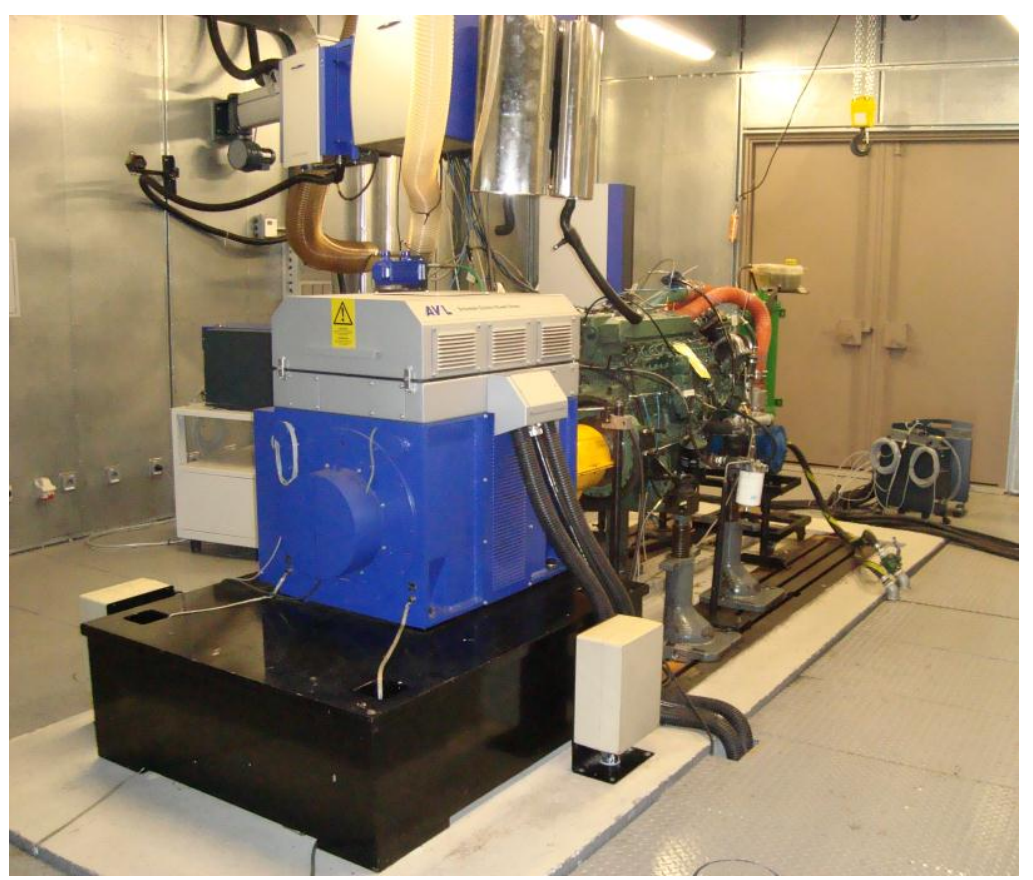

Figura 3. Banco de Provas de Motores do Centro de Tecnologia da MAHLE Metal Leve S/A.

Para que fosse possível alcançar uma baixa dispersão, os seguintes equipamentos foram utilizados:

- Medição de Combustível: Medidor de fluxo de combustível do tipo Coriolis, conforme figura 4 e controlador de temperatura de combustível.

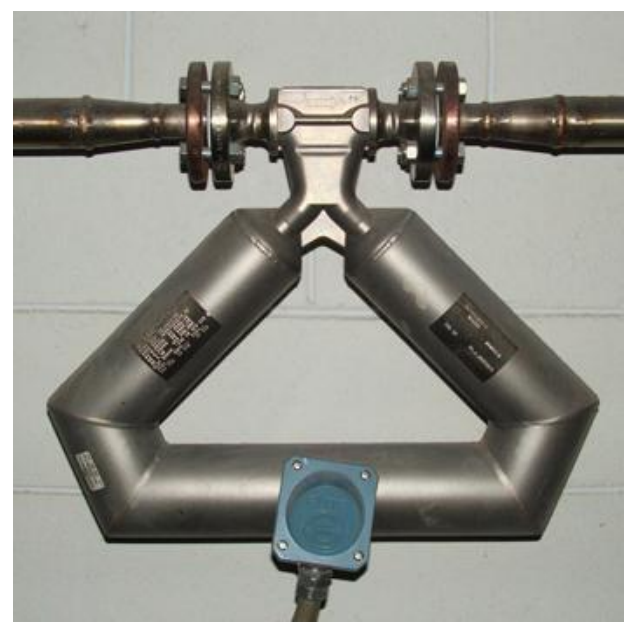

Figura 4. Medidor de Fluxo de Combustível - Coriolis

Com a utilização deste medidor de fluxo de combustível é possível a medição de forma continua até a taxa de $10 \mathrm{~Hz}$, obtendo assim grande população amostral que permitira análise mais detalhada da dispersão da medição.

- Sistema de análise da combustão: Medição de Pressão de Cilindro através de sensores piezoelétricos, conforme figura 5 . 


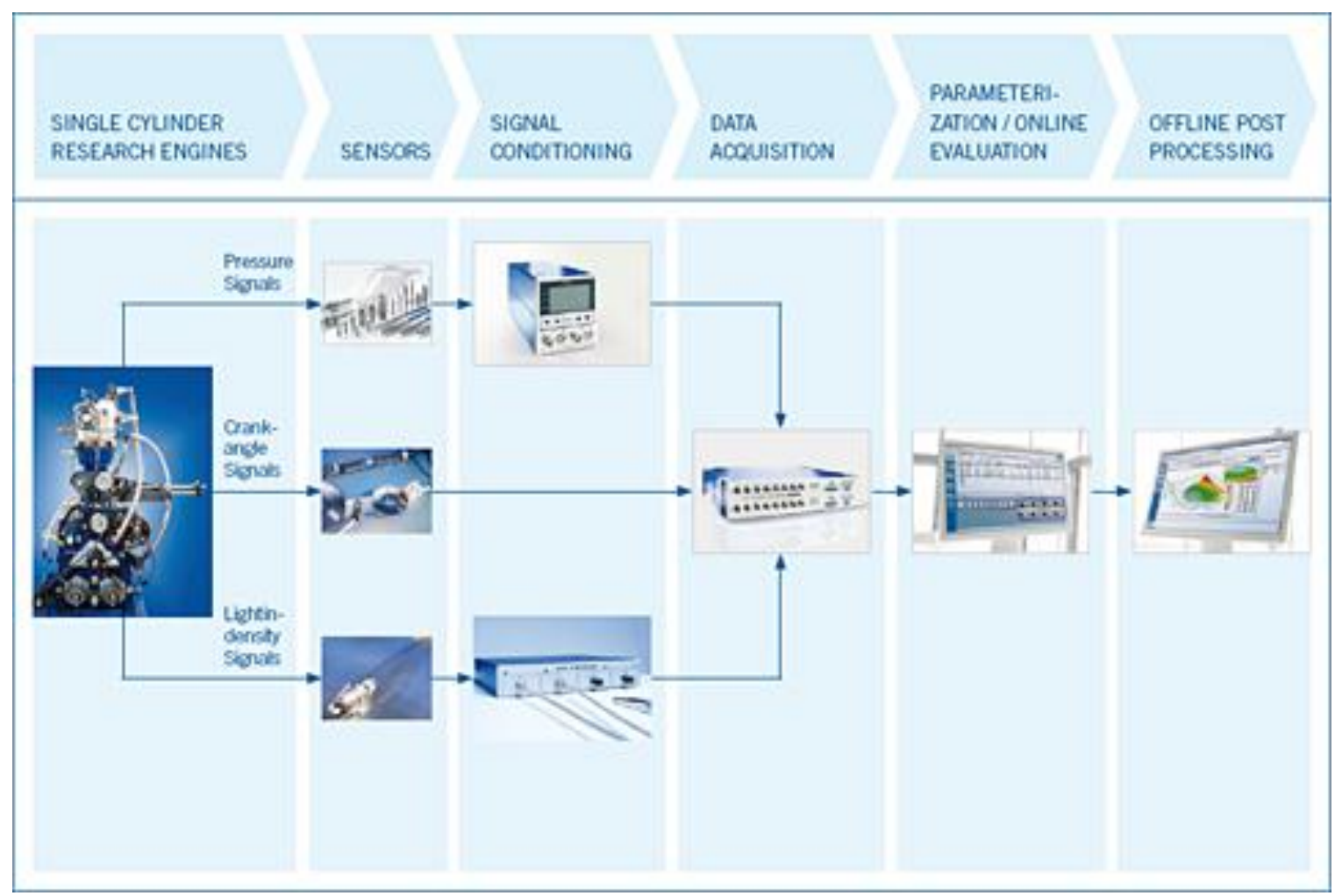

Figura 5. Sistema para análise da combustão[6]

O sistema de análise da combustão tem a principal função de avaliar a queima do combustível e geração do trabalho, permitindo a identificação de qualquer anormalidade que possa influenciar no resultado e na repetibilidade da medição.

Os demais sistemas utilizados estão integrados no banco de provas de motores e são convencionais para este tipo de aplicação.

Durante a execução dos testes os parâmetros mais importantes a serem monitorados e controlados com baixa dispersão são:

- Temperatura e pressão do ar de admissão do motor

- Temperatura e pressão do ar após cooler

- Temperatura do líquido de arrefecimento

- Temperatura e pressão do óleo lubrificante

- Temperatura o do combustível

- Início das Injeções

- Pressão de injeção

- Posição do Pedal de acelerador

- Tensão de alimentação da ECU

- Pressão do turbo alimentador

- Posição do atuador do turbo

- Correções pela ECU

- Restrição de escapamento 


\section{MÉTODOS}

Para avaliação do consumo de combustível optou-se pelo mapeamento do motor, conforme faixas de trabalho do mesmo, portanto o mapeamento foi executado nos seguintes pontos:

Tabela 1. Mapeamento do Motor

\begin{tabular}{|c|c|c|c|c|c|}
\hline $\begin{array}{c}\text { Rotação } \\
\left(\text { min }^{-1}\right)\end{array}$ & \multicolumn{5}{|c|}{ Carga } \\
\hline 1800 & $100 \%$ & $80 \%$ & $60 \%$ & $40 \%$ & $20 \%$ \\
\hline 1700 & $100 \%$ & $80 \%$ & & & \\
\hline 1600 & $100 \%$ & $80 \%$ & $60 \%$ & $40 \%$ & $20 \%$ \\
\hline 1500 & $100 \%$ & $80 \%$ & & & \\
\hline 1400 & $100 \%$ & $80 \%$ & $60 \%$ & $40 \%$ & $20 \%$ \\
\hline 1300 & $100 \%$ & $80 \%$ & & & \\
\hline 1200 & $100 \%$ & $80 \%$ & $60 \%$ & $40 \%$ & $20 \%$ \\
\hline 1100 & $100 \%$ & $80 \%$ & & & \\
\hline 1000 & $100 \%$ & $80 \%$ & $60 \%$ & $40 \%$ & $20 \%$ \\
\hline
\end{tabular}

O mapeamento é executado iniciando na rotação mais alta à plena carga e deve seguir na mesma rotação reduzindo a carga, então muda-se para rotação seguinte e segue mesma sequência.

Antes de cada medição o motor é estabilizado até que a incerteza da medição de consumo de combustível seja inferior a $0,2 \%$, considerando o desvio padrão das últimas 30 medidas aquisitadas a $1 \mathrm{~Hz}$. Após a estabilização são executadas 10 aquisições de dados consecutivas, sendo cada uma a media de 30 segundos.

Todos os passos do mapeamento são repetidos por três vezes, de forma que um mapeamento completo do motor será constituído pela média de três ciclos de medição, como representado na figura 6 .

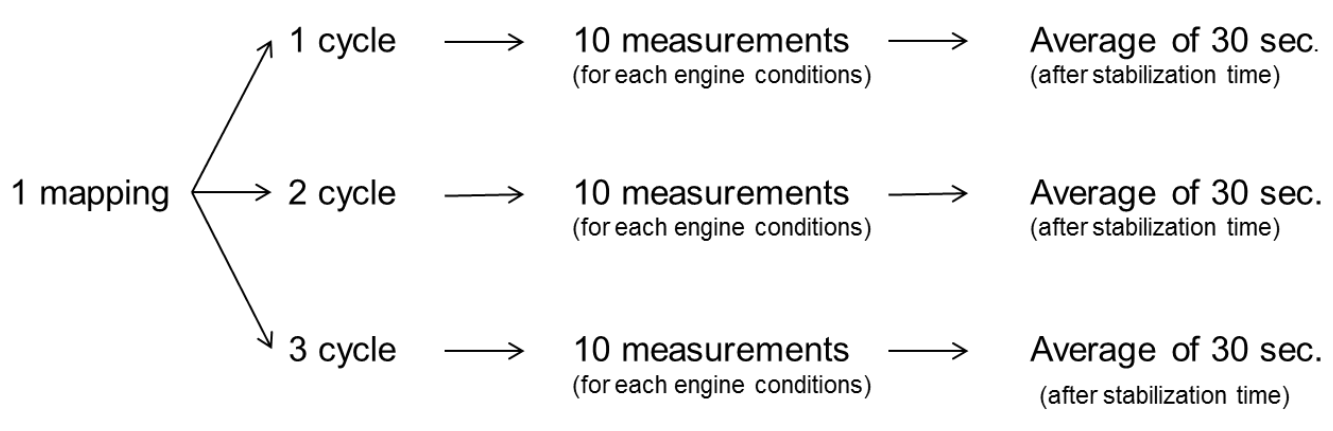

Figura 6.Sequência de medição.

No caso de comparativo de pacotes de componentes de motor, todo o procedimento é executado para uma configuração referência do motor e novamente utilizando o pacote de componentes proposto. Entre as montagens do motor deve-se tomar o cuidado para que toda a instrumentação seja mantida.

Durante cada ciclo de aquisição de dados o desvio máximo aceitável entre as 10 medições consecutivas é de $0,5 \%$. A diferença entre as médias de cada ciclo deve ser menor do que $0,3 \%$ para que o ponto do mapa seja considerado válido. 
Todas as medições devem ser realizadas utilizando o mesmo lote de combustível.

\section{RESULTADOS}

Os resultados da validação do protocolo demonstraram que existe boa correlação entre os ciclos de medição, sendo que a dispersão obtida é na maioria dos casos menor do que $0,3 \%$, conforme demonstrado na figura 7. A dispersão tende a aumentar para os pontos de menor carga, devido à influência dos erros nas medições e oscilação do torque nesta região.

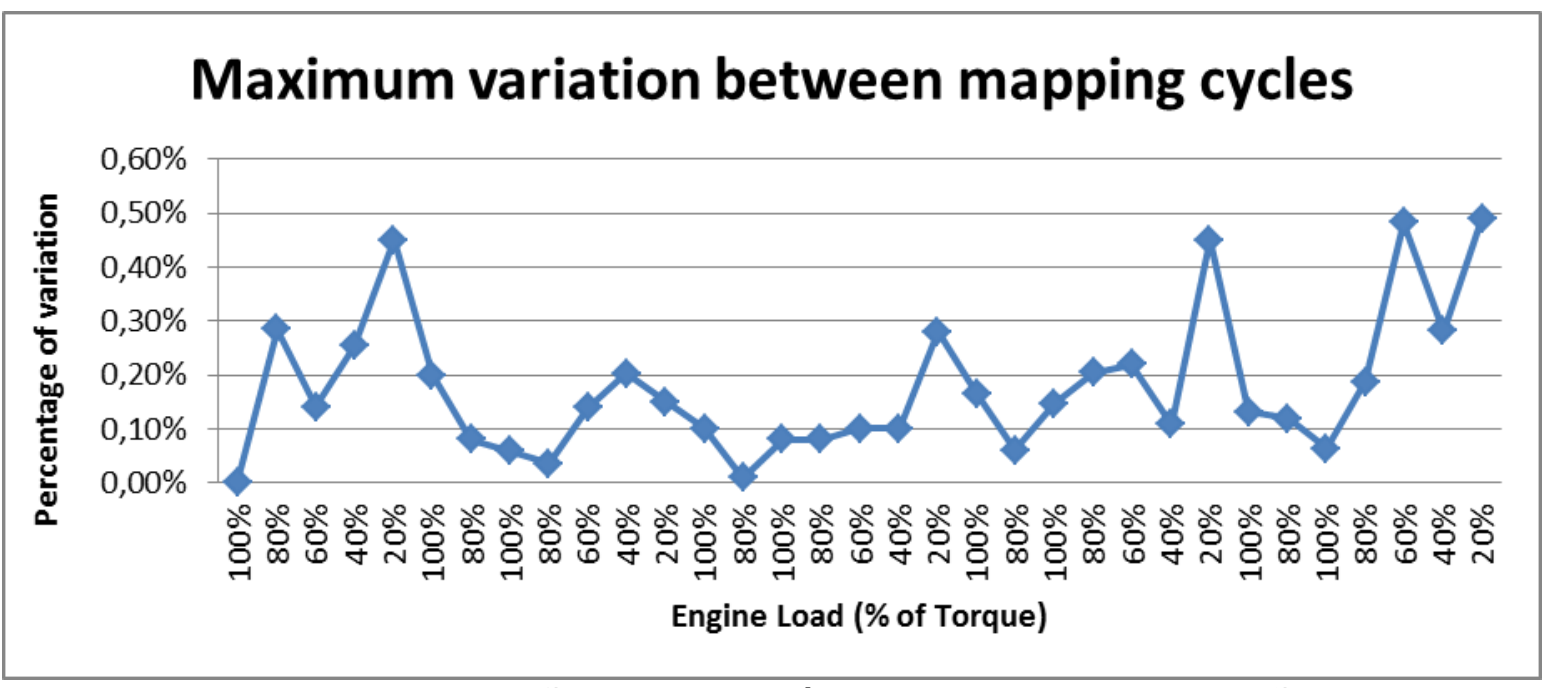

Figura 7. Variação entre as médias dos ciclos de medições

Todavia, os pontos que apresentam dispersão maior do que 0,3 \% representam uma quantidade menor do que $15 \%$ da totalidade, podendo ser descartados sem grandes prejuízos na elaboração do mapa de consumo de combustível do motor. No geral, nas regiões de menores cargas as dispersões obtidas foram da ordem de $0,3 \%$, enquanto que em regiões de cargas mais altas as dispersões obtidas foram da ordem de $0,1 \%$.

Uma vez obtidos os valores de consumo específico médio para cada ponto planejado e utilizando interpolação linear, são construídos os mapas de consumo de combustível específico para cada configuração do motor.

Para facilitar a visualização são geradas curvas de iso-consumo, conforme representado nas figuras 8 e 9 . 


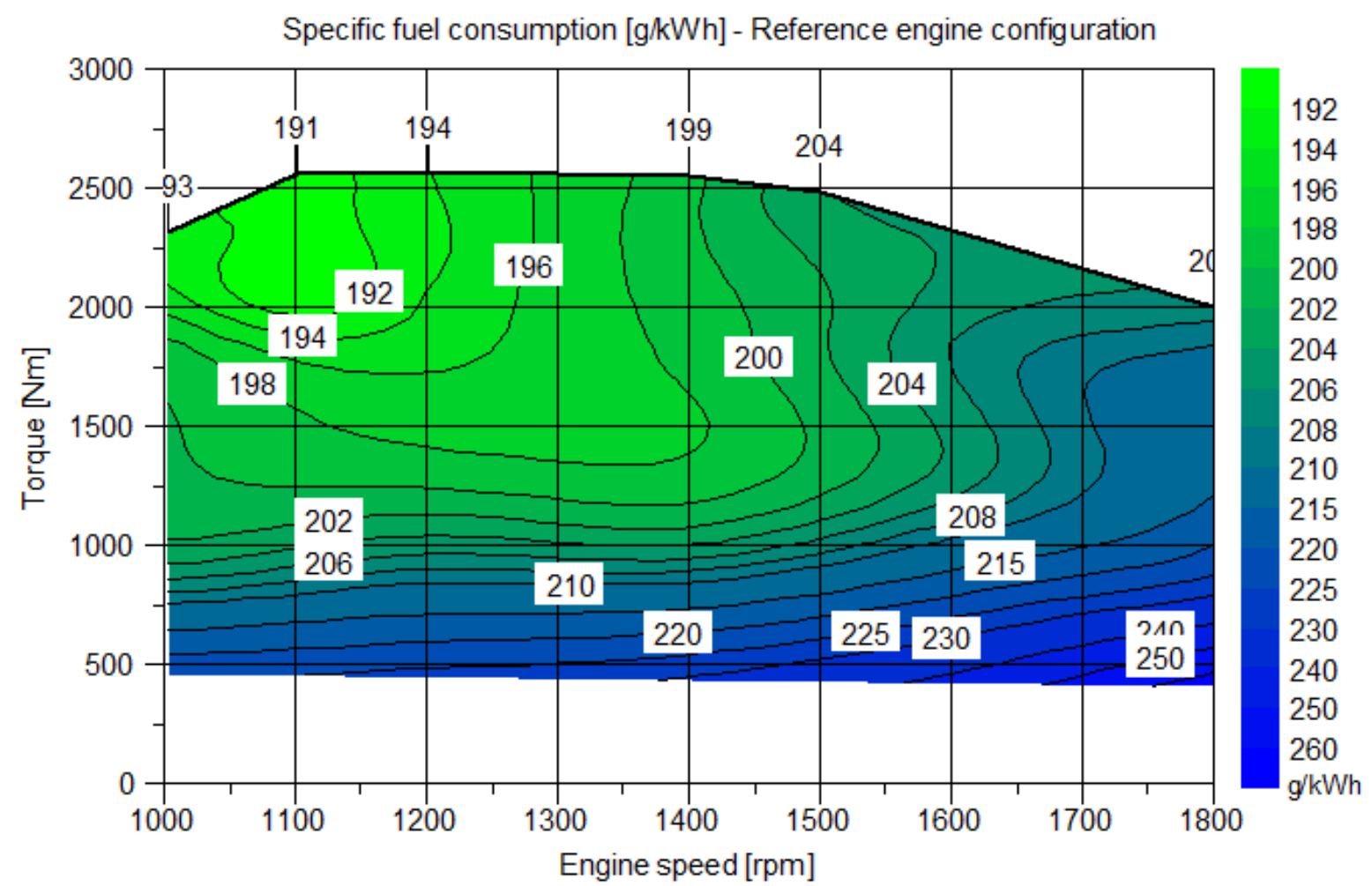

Figura 8. Mapeamento motor referência

Specific fuel consumption [g/kWh] - Proposed components pack

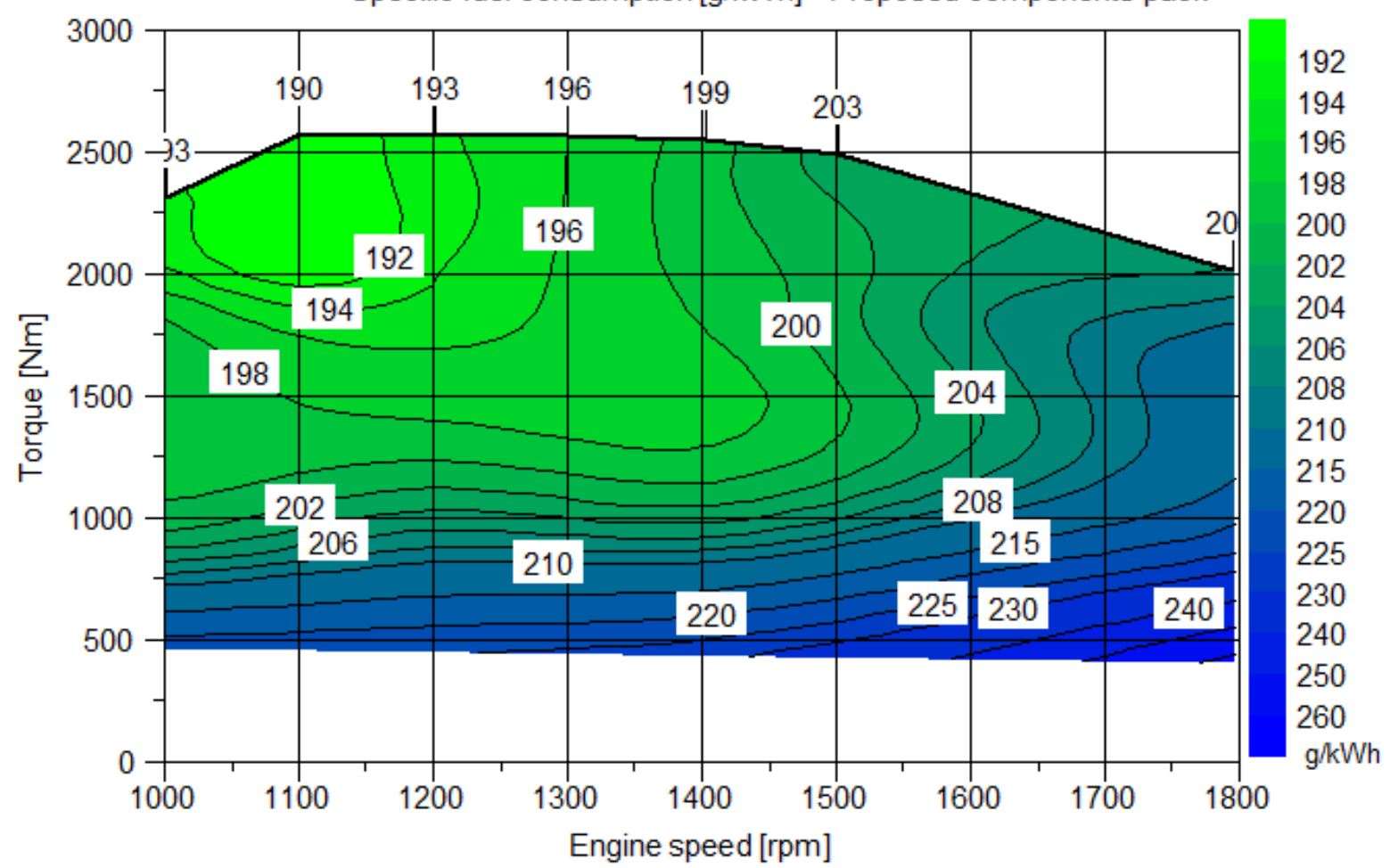

Figura 9. Mapeamento motor com pacote de componentes de baixo atrito.

Uma vez obtidos os mapas de consumo de combustível para cada configuração do motor é possível sobrepô-los calculando sua diferença percentual. Desta forma pode-se verificar a redução de consumo específico de combustível percentual. A 
figura 10 representa o mapa com os valores calculados da diferença percentual entre os mapas das figuras 8 e 9 , sendo que os valores positivos indicam redução no consumo específico de combustível do motor quando utilizando o pacote de componentes proposto.

Reduction of SFC [\% of $\mathrm{g} / \mathrm{kWh}$ ] (Reference $\mathrm{x}$ Proposal)

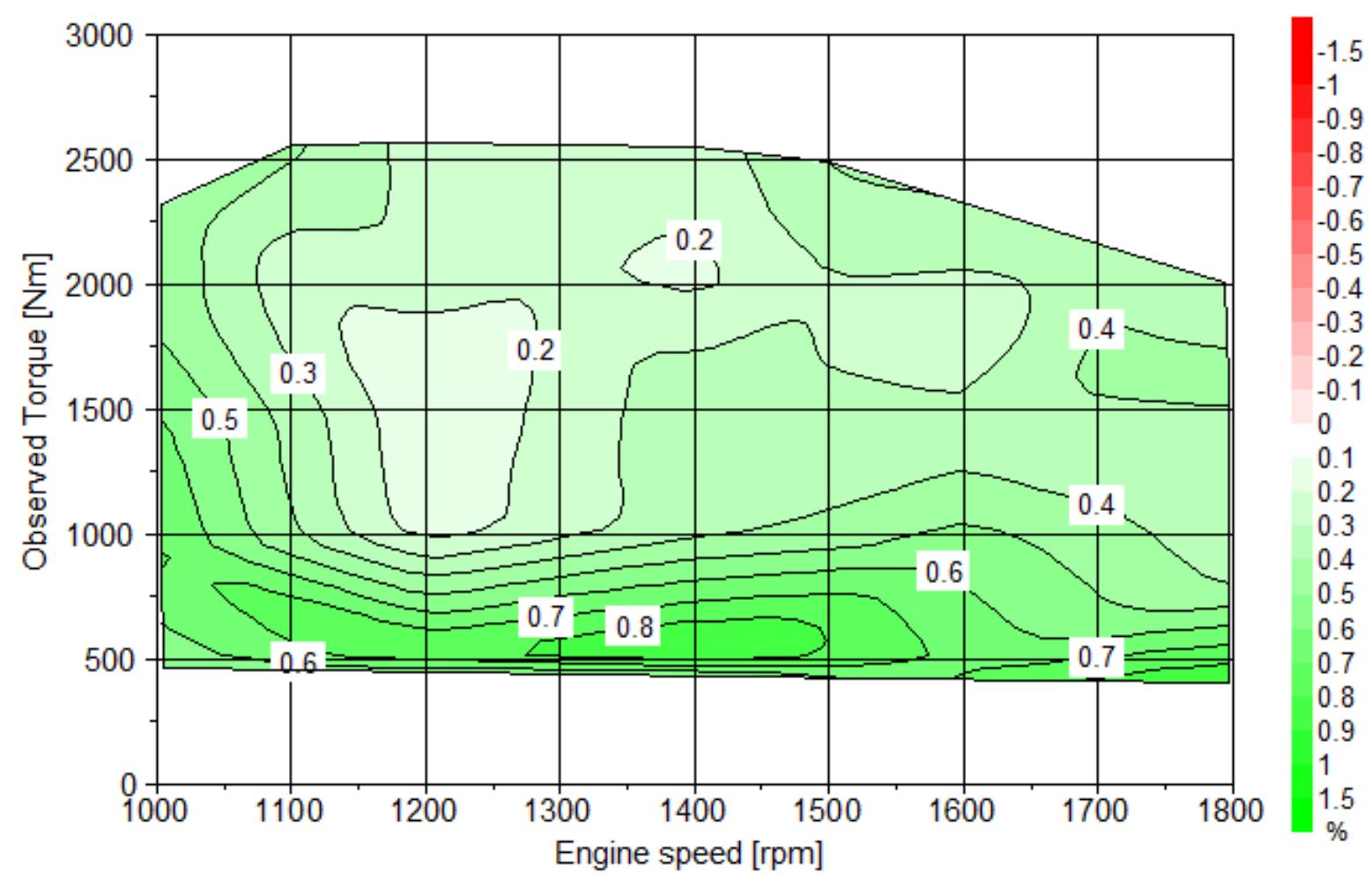

Figura 10. Diferenças entre mapas: referência vs. pacote de componentes de baixo atrito.

\section{CONCLUSÃO}

Através da elaboração do protocolo especifico para determinação de consumo de combustível em motores diesel, no qual os principais parâmetros de influência na variação dos resultados são identificados e controlados, foi possível estabelecer um procedimento de medição de consumo de combustível com baixa dispersão.

Os resultados obtidos demonstraram que as dispersões nas medições são dependentes da região de trabalho do motor. Nas regiões de cargas menores as dispersões obtidas foram da ordem de $0,3 \%$, enquanto que em regiões de cargas mais altas as dispersões obtidas foram da ordem de $0,1 \%$.

Assim, mantendo as medições de combustão estabilizadas e conhecidas, pode-se comparar variações no consumo de combustível que sejam maiores que a dispersões apresentadas, como sendo o resultado das modificações dos componentes.

Sendo assim, o protocolo se apresenta com uma ferramenta importante para o desenvolvimento de componentes de motor como também para embasamento dos fabricantes de motor sobre as diferentes áreas a serem melhoradas, seja por 
componentes de menor atrito, sejam por soluções relacionadas aos sistemas de combustão.

\section{REFERÊNCIAS}

[1] The FIA Foundation. 50 by $\mathbf{5 0}$ Global Fuel Economy Symposium Report. Disponível em: www.fiafoundation.org/50by50/ . Acesso em: 25/04/2013.

[2] Transport Outlook 2008. Focusing on $\mathrm{CO}_{2}$ Emissions from Road Vehicles, Discussion Paper 2008-13, OECD/ITF 2008. Disponível em:

http://www.internationaltransportforum.org/itrc/DiscussionPapers/DP200813.pdf . Acesso em: 25/04/2013.

[3] SCHANTL, Rainer; Physical limitations of fuel consumption measurement. ASAM Open Technology Forum Europe 2012. Stuttgart. 2012.

[4] HEYWOOD, John. Internal Combustion Engine Fundamentals. McGraw-Hill, 1988

[5] SILVA, E. L.; BERGANTIM, L. C.; CAMARGO, C. R.; CARLINI, R. Z. Monocylinder floating liner engine for friction determination. SIMEA. 2012

[6] Combustion measurement (Indicating). Disponível em:

https://www.avl.com/combustion-measurement Acesso em: 28/04/2013.

[7] SILVA, E. L. Propostas para otimização do consumo energético em motores de combustão interna do ciclo Otto através da redução das perdas por atrito. 2013, 73p. Trabalho de Conclusão de Curso - Escola Politécnica da Universidade de São Paulo, São Paulo, 2013.

[8] Basshuysen, R.; Schafer, F. Internal combustion Engine Handbook. SAE International, 2004 